
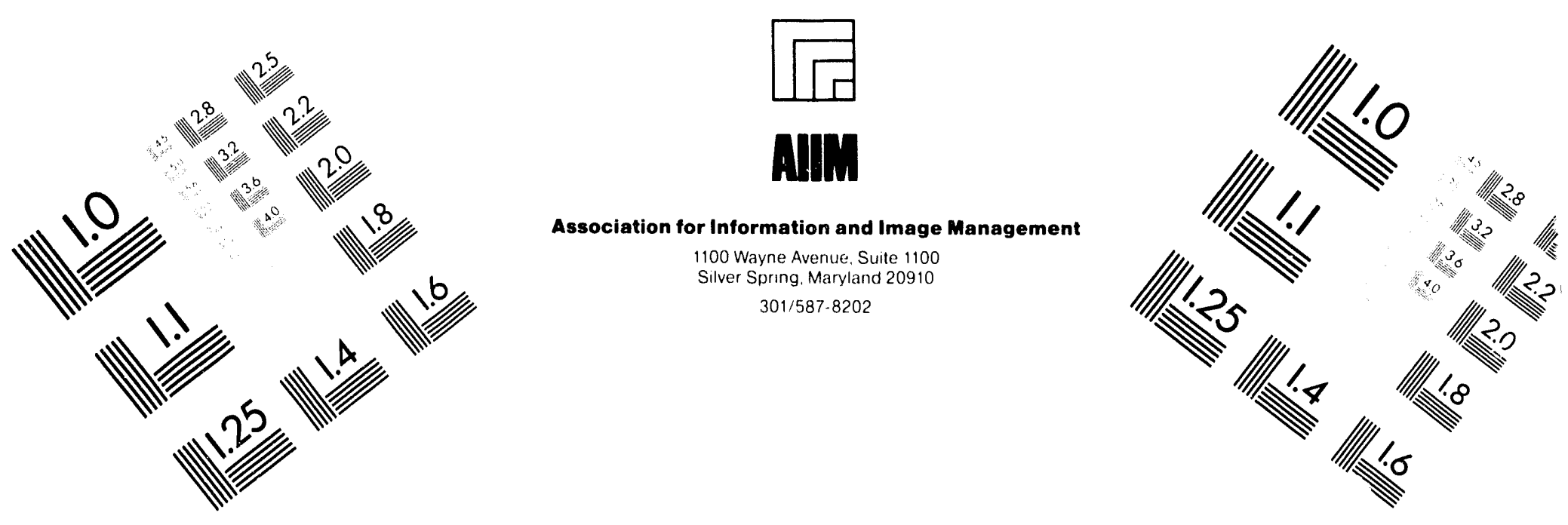

\title{
Centimeter
}

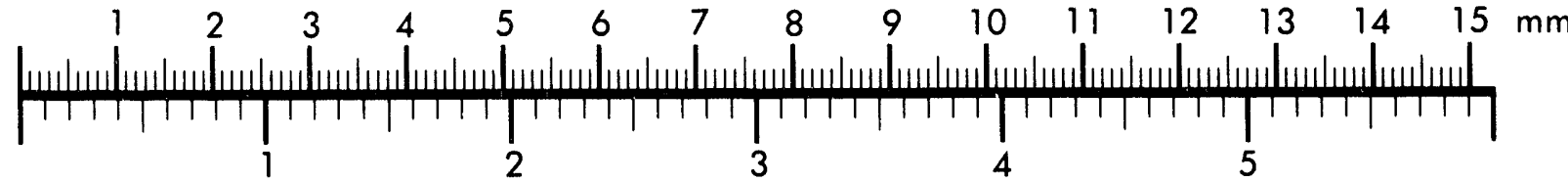

Inches
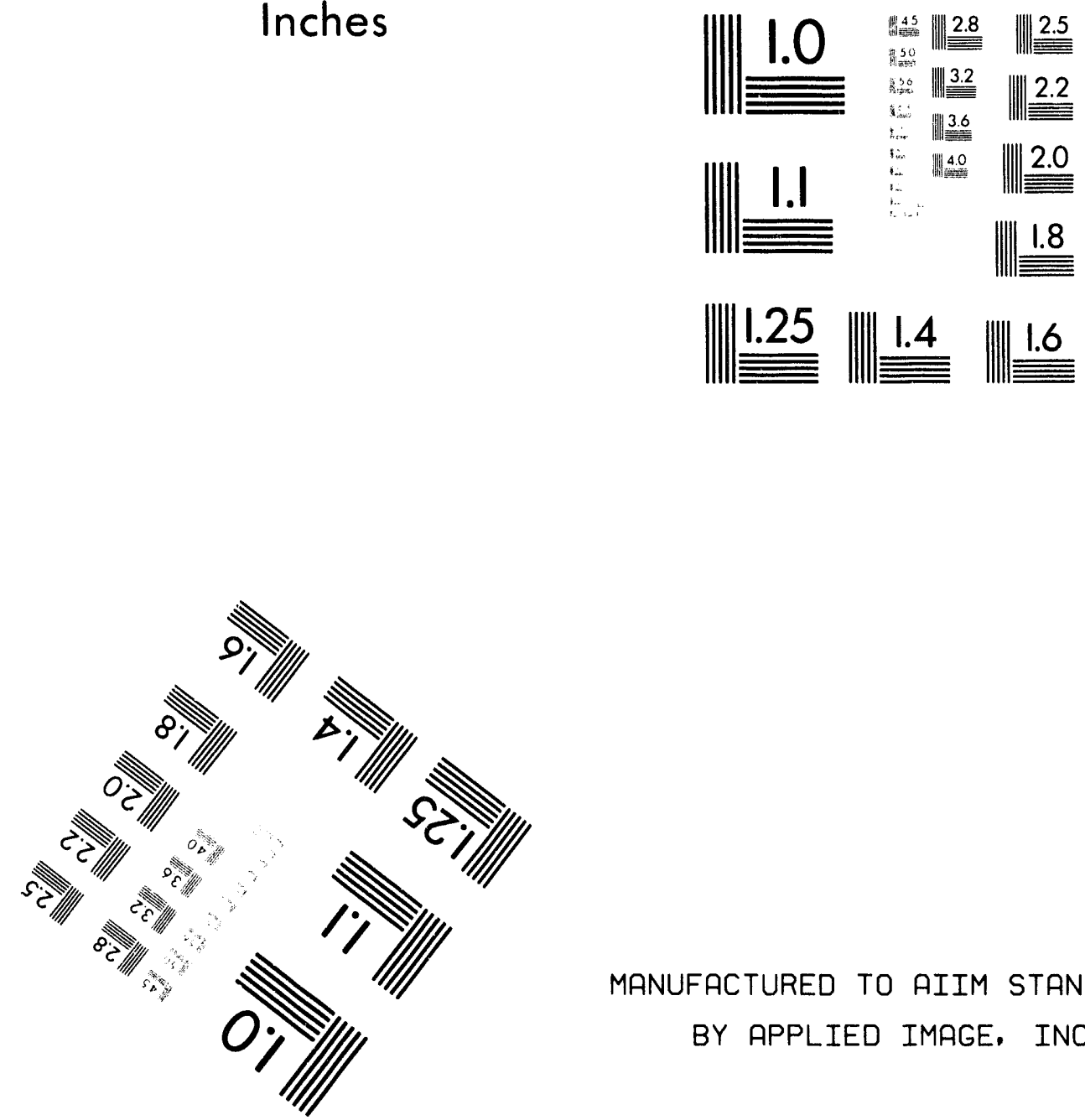

MANUFACTURED TO AIIM STANDARDS

BY APPLIED IMAGE. INC.

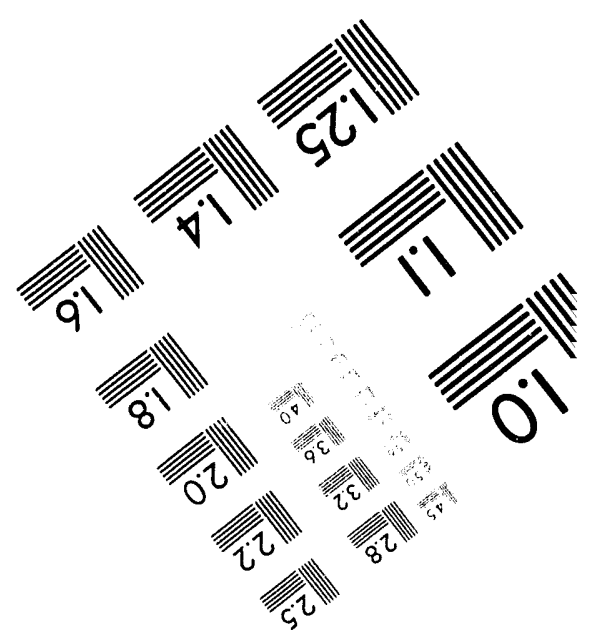



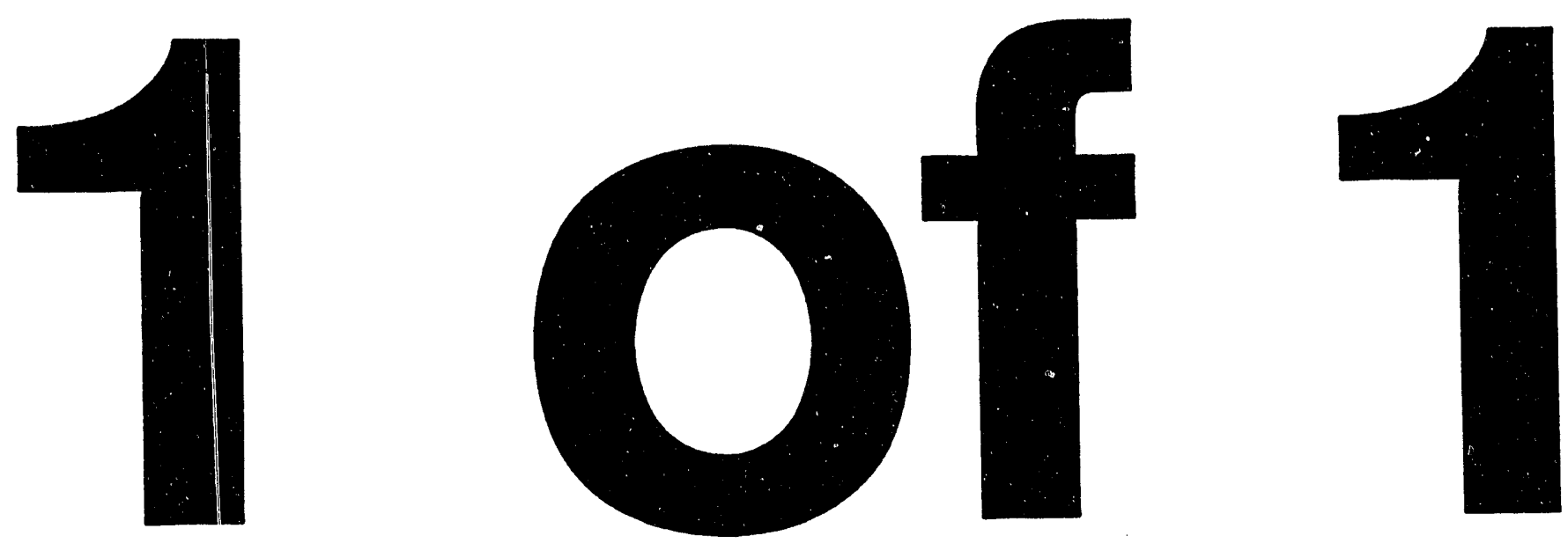
DE-AC22-92PC91346-6

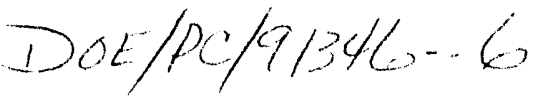

\section{DEVELOPMENT OF THE INTEGRATED ENVIRONMENTAL CONTROL MODEL:}

Performance and Cost Models for Fabric Filters

January - Marek 1994

Quarterly Progress Report

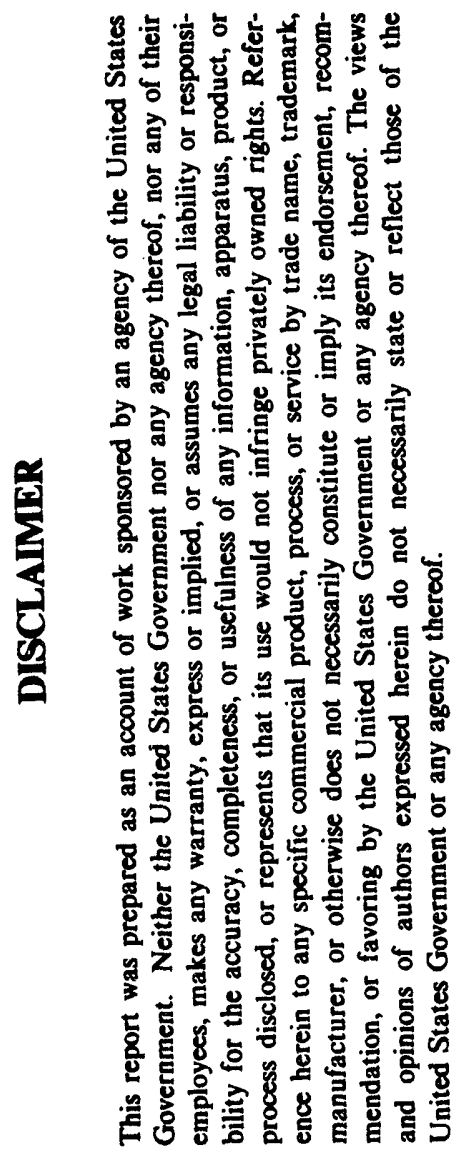

to

Pittsburgh Energy Technology Center

U.S. Department of Energy

Pittsburgh, PA 15236

from

Center for Energy and Environmental Studies

Carnegie Mellon University

Pittsburgh, PA 15213

Prepared by

Jayant R. Kalagnanam

Edward S. Rubin

April 27, 1994

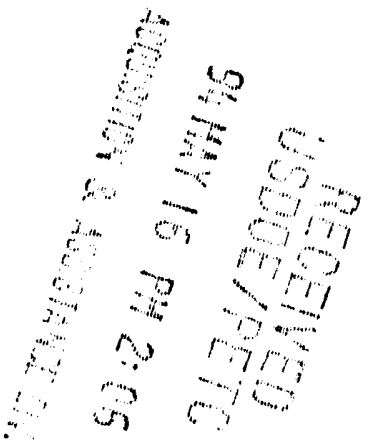




\section{Table of Contents}

1.0 Introduction

2.0 Scope of this Report

3.0 Fabric Filters for Electric Utilities

3.1 Fabric Filter Design

3.2 Cost Models for Fabric Filters

3.2.1 Reverse Gas Systems

3.2.2 Pulse-Jet Systems

References 


\subsection{Introduction}

The purpose of this contract is " ) develop and refine the Integrated Environmental Control Model (IECM) created and enhanced by Carnegie Mellon University (CMU) for the U.S. Department of Energy's Pittsburgh Energy Technology Center (DOE/PETC) under contract Numbers DEFG22-83PC60271 and DE-AC22-87PC79864.

In its current configuration, the IECM provides a capability to model various conventional and advanced processes for controlling air pollutant emissions from coal-fired power plants before, during, or after combustion. The principal purpose of the model is to calculate the performance, emissions, and cost of power plant configurations employing alternative environmental control methods. The model consists of various control technology modules, which may be integrated into a complete utility plant in any desired combination. In contrast to conventional deterministic models, the IECM offers the unique capability to assign probabilistic values to all model input parameters, and to obtain probabilistic outputs in the form of cumulative distribution functions indicating the likelihood of different costs and performance results.

The most recent version of the IECM, implemented on a Macintosh II computer, was delivered to DOE/PETC at the end of the last contract in May 1991. The current contract will continue the model development effort to provide DOE/PETC with improved model capabilities, including new software developments to facilitate model use and new technical capabilities for analysis of environmental control technologies. Integrated environmental control systems involving precombustion, combustion, and post-combustion control methods will be considered.

The work in this contract is divided into two phases. Phase I deals with further developing the existing version of the IECM and training PETC personnel on the effective use of the model. Phase II deals with creating new technology modules, linking the IECM with PETC databases, and training PETC personnel on the effective use of the updated model.

\subsection{Scope of this Report}

The present report summarizes recent progress on the Phase I effort during the period January 1 , 1994 through March 30,1994. This report summarizes our progress to date in refining the existing analytical models implemented in the IECM. In this report we describe the development of analytical models for the performance and costs of high-performance particulate control technologies, focusing on fabric filters. We pay special attention to developing models which can be used to estimate costs for systems whose performance is up to a factor of three below the present NSPS standards of $0.03 \mathrm{lb} / \mathrm{MMBtu}$. Typically, the cost models relate the capital costs and the operating and maintenance (O\&M) costs to process parameters and the costs of labor and materials. The capital cost models are anchored to a base capital cost for a specific size unit and adjusted according to the actual or design parameters. The performance models are constructed to estimate the process parameters for a desired level of emissions control. The primary motivation for these models is to estimate the costs of complying with environmental standards on a basis which reflects recent advances in control technology. Finally, we incorporate the uncertainties in various process parameters and inputs costs so as to allow a more rational and robust basis for comparing different technologies. 
In the following sections we discuss the initial development of the performance and cost models for fabric filters followed by a numerical example which illustrates the use of these new models. The next quarterly report will provide a similar update of the IECM electrostatic precipitator models, plus a brief discussion of the comparative advantages of different particulate control.

\subsection{Fabric Filters for Electric Utilities}

Fabric filters have been very effective in achieving the 1979 NSPS limits for coal-fired power plants. As a result, over 100 baghouses associated with $20,000 \mathrm{MW}$ of generating capacity are in operation in the U.S. utility industry (Cushing, Bush, \& Synder, 1990; Kumar \& Feldman, 1994; Puille, 1985). These units routinely perform at efficiencies above $99.9 \%$ and produce clear stack plumes with less than $1 \%$ opacity. These fabric filters have been in operation with pulverized coal-fired boilers of various designs including some which are installed on fluidized bed combustion boilers. Operating experience in the U.S. has been predominantly with reverse gas cleaning (about $90 \%$ ) with low air-to-cloth ratio baghouses. Bag failure rate has stabilized at about $1 \%$ per year through the 1980 s and four-year bag life is now fairly common. In particular, there has been virtually no reduction in boiler availability due to baghouse malfunction since any target compartment can be brought off-line for baghouse replacement.

In this section, we will first discuss the important design parameters for fabric filters and their effects on capital and O\&M costs. The design parameters are dependent on the bag cleaning method and this will be explicated. Cost models parametrized by design parameters are developed, along with a numerical example to illustrate the cost models.

\subsection{Fabric Filter Design}

Fabric filters are essentially huge vacuum cleaners consisting of a large number of long tubular filter bags arranged in parallel flow paths. As the ash-laden flue gas passes through these filters, almost all of the particulate matter is removed. Ash that accumulates on the bags is removed periodically by cleaning. For properly designed fabric filters, the size of the system is independent of the removal efficiency. Thus, efficiency can be improved without an associated increase in capital costs. The issue of a proper design is characterized by a number of parameters which we now discuss in some detail. We also provide the default operating values used in the industry today with an estimate of uncertainty to bound the variation observed in practice (Belba, Grubb, \& Chang, 1992; Carr \& Smith, 1984; Cushing, et al., 1990; Scheck, Mora, Belba, \& Horney, 1985; Sloat, Gaikwad, \& Chang, 1993).

There are various bag cleaning techniques that are used and this influences other process parameters in a non-trivial way. There are four available bag cleaning methods:

(1) Reverse Gas Cleaning (RG): This is an off-line bag cleaning technique in which an auxiliary fan forces a relatively gentle flow of filtered flue gas backwards through the bags causing them to partially collapse and dislodge the dustcake. Over $90 \%$ of the U.S. utility baghouses use reverse-gas cleaning.

(2) Reverse Gas/sonic cleaning (RG/S): A variation of $R G$ in which low frequency pneumatic horns sound simultaneously with the flow of reverse gas to add energy to the dustcake removal process. 
(3) Shake/Deflate Cleaning (S/D): A method for offline cleaning. The bags are mechanically shaken immediately after or while a small quantity of filtered gas is forced back to relax the bags. The amount of filtered gas used is smaller than that used in RG cleaning.

(4) Pulse-Jet Cleaning (PJ): A method for on-line cleaning in which pulses of compressed air are blown down inside and through the bags to remove dustcake while the bags are filtering flue gas. Wire support cages are used to prevent bag collapse during filtration and ash is collected outside of the bags.

The choice of the bag cleaning method is usually based on the type of coal being used (hence the filterability of the ash) and the historical experience with filtering the particular kind of ash. The choice of the bag cleaning method is a design decision and for the purposes of our models we assume that this is specified by the user. While reverse gas cleaning has been dominant in the past, studies have shown that it is not as effective as other methods in achieving low capital and O\&M costs (Scheck, et al., 1985). RG/S and S/D impart more cleaning energy to the bags which results in thinner dustcakes and lower pressure drop. Such systems also can be at higher air-tocloth (A/C) ratios, reducing costs. It appears that more recently, $\mathrm{RG} / \mathrm{S}$ is emerging as a method of choice for full-scale, low A/C ratio utility baghouses on pulverized coal-fired boilers (Cushing, et al., 1990).

The most critical parameter in the operation of a baghouse is the relative system size which is characterized in terms of air-to-cloth ratio, defined as the volumetric flow rate of flue gas divided by the total bag cloth area. This ratio has the units of $\mathrm{acfm} / \mathrm{ft}^{2}$. The $\mathrm{A} / \mathrm{C}$ ratio is determined based on the bag cleaning method, which controls the residual quantity of the material remaining on the bags. This in turn affects the resistance to gas flow and determines the pressure drop. Utility baghouses typically use $\mathrm{A} / \mathrm{C}$ ratios of $1.5-4.0 \mathrm{acfm} / \mathrm{ft}^{2}$ (net-net) ${ }^{1}$ depending on the bag cleaning method. The cost of a baghouse is determined by the unit size which in turn depends on the gross $\mathrm{A} / \mathrm{C}$ ratio and the volumetric flow rate. Given that the $\mathrm{A} / \mathrm{C}$ ratio is the primary determinant of the unit size, and hence the capital and operating costs, it is desirable to operate at the highest $\mathrm{A} / \mathrm{C}$ ratio that comfortably meets the performance specifications. Table 1 provides the typical values used for $\mathrm{A} / \mathrm{C}$ ratio for various baghouse types based on industry experience (Belba, et al., 1992; Bustard, Cushing, \& Chang, 1992; Cushing, et al., 1990; Puille, 1985; Sloat, et al., 1993).

Baghouse pressure drop is caused by pressure losses in gas flow as it moves through the bag fabric and dustcake. The pressure drop is usually measured in inches of water gauge or column (iwg or iwc) and is a measure of the energy required to move flue gas through the baghouse structure and bags. Flange-to-flange pressure drop is the pressure difference measured between the baghouse inlet and outlet flanges. It is the sum of ductwork and tubesheet pressure drops. Tubesheet pressure drop is measured across the tubesheet in a single compartment and consists largely of the pressure drop across the dustcake. Tubesheet pressure drop is the largest component of the flange-to-flange pressure drop and is useful since it can be controlled by the

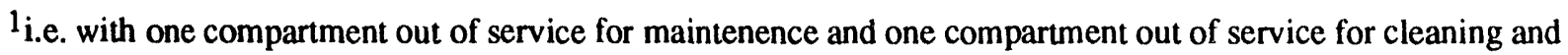
including reverse or deflation gas flow. Gross $\mathrm{A} / \mathrm{C}$ ratio refers to all compartments being in service.
} 
operator. However, it is the flange-to-flange pressure drop that is used in terms of a unit's energy consumption during operation and is used for sizing the ID fan. Baghouses are generally designed for a flange-to-flange pressure drop of about $6-8$ in. $\mathrm{H}_{2} \mathrm{O}$ regardless of the cleaning method as a result of constraints from induced draft fans, ductwork stiffening, and other design details. Typical values for tubesheet pressure drop for given values of $\mathrm{A} / \mathrm{C}$ ratios based on industry experience are also provided in Table 1.

Table 1. Typical Fabric Filter Design Parameters

\begin{tabular}{|l|l|l|l|}
\hline Baghouse Type & $\begin{array}{l}\text { A/C Ratio net-net } \\
\left(\mathrm{acfm} / \mathrm{ft}^{2}\right)\end{array}$ & $\begin{array}{l}\text { Average tubesheet } \\
\Delta \mathrm{P}\left(\mathrm{in} . \mathrm{H}_{2} \mathrm{O}\right)\end{array}$ & $\begin{array}{l}\text { Average Bag Life } \\
(\text { years })\end{array}$ \\
\hline Reverse Gas & $1.7-2.0$ & $3 \times(\mathrm{A} / \mathrm{C})+/-20 \%$ & $3-5$ \\
\hline Reverse Gas Sonic & $1.7-2.0$ & $2.5 \times(\mathrm{A} / \mathrm{C})+/-20 \%$ & $3-5$ \\
\hline Shake-Deflate & $2.5-3.0$ & $2 \times(\mathrm{A} / \mathrm{C})+/-15 \%$ & $2-4$ \\
\hline Pulse Jet & $4.0-4.5$ & $1.3 \times(\mathrm{A} / \mathrm{C})+/-50 \%$ & $2-4$ \\
\hline
\end{tabular}

U.S. utilities largely use woven fiberglass bag fabric because of high flue gas temperatures. Fiberglass can withstand temperatures up to $500 \mathrm{~F}$ and can be textured to control dustcake formation. But it is also susceptible to abrasion wear. The choice of the bag fabric affects the cost of the bag. Bags generally fall into two size categories: $30-36 \mathrm{ft}$ in length and $1 \mathrm{ft}$ in diameter, and $20-22 \mathrm{ft}$ in length and $8 \mathrm{in}$. in diameter. Bag life is generally not an issue (except for manufacturing defects and improper installation) and is usually between 3-5 years. All these parameters influence both the capital and operating costs. Once again, for the purposes of the models developed here these parameters are treated as design variables to be specified by the user. The effect of these choices on the cost of the baghouse has been modeled.

\subsection{Cost Models for Fabric Filters}

The cost models for the four types of fabric filters are developed for both capital costs and operation and maintenance (O\&M) costs. These models follow the economic premises for cost development and breakdown developed by EPRI. The capital costs are developed on a process area by process area basis and the O\&M are developed to reflect the fixed and the variable operating costs. The cost areas are shown below in Table 2.

Table 2. Process Areas for Fabric Filter cost Models

\begin{tabular}{ll}
\hline Process Area & Description \\
\hline 10 & Collectors \\
20 & Ductwork \\
30 & Fly Ash Handling System \\
40 & Differential Cost \\
\hline
\end{tabular}


The models developed in this report are based on price quotes from equipment vendors obtained for EPRI (Gaikwad \& Sloat, 1992; Scheck, et al., 1985). The main difference in our treatment of these costs is that we have developed cost models parametrized by operating design parameters on a process area basis. In contrast, the EPRI models use aggregate costs (such as total capital requirement) for the development of parametrized models. In this subsection, we first present the methodological basis used for model development and then present the cost models.

In the development of cost models, we have treated the Reverse-Gas, Reverse Gas/Sonic and the Shake-Deflate baghouses as one class of systems and the Pulse-Jet fabric filter separately as another class. Engineering experience suggests that the difference in the economics between $\mathrm{RG}, \mathrm{RG} / \mathrm{S}$, and SD baghouses can be treated parametrically through the operating design parameters A/C, $\Delta \mathrm{P}$, and bag life (Scheck, et al., 1985). This implies that the difference in costs between a RG baghouse and a RG/S baghouse is largely accounted by the difference in the design parameters and can be described by one set of cost models. The cost models for Pulse-Jet baghouses have been developed separately since it is a new technology and there is not sufficient experience to treat it parametrically in the context of the RG models.

The major design parameters which can significantly impact the total system cost of the fabric filter are gas flow volume (which depends on the generating unit size), $A / C$ ratio, the flange-toflange pressure drop in the baghouse, bag life and the bag fabric that is used for filtering. The costs of baghouses for different unit sizes and with variations in the above parameters is reflected in the models. The sensitivity of baghouse costs to variations in these parameters is analyzed to parametrize the cost models. We will now discuss in detail the experimental design and development the cost models for each system of baghouses separately.

\subsubsection{Reverse Gas Systems}

The experimental design used to choose different vectors of the design parameters for capital cost estimation (Scheck, et al., 1985) is shown in Table 3.

Table 3. Range of Model Design Parameters

\begin{tabular}{|l|l|l|l|}
\hline Case & Size in MW (acfm) & $\begin{array}{l}\text { A/C Ratio (gross) } \\
\text { acfm/ft }\end{array}$ & $\begin{array}{l}\text { Bags per Compartment } \\
\text { (No. of Compartments) }\end{array}$ \\
\hline Base & $500 \mathrm{MW}(1.9 \mathrm{M})$ & 2.0 & $360(28)$ \\
\hline 1 & $250 \mathrm{MW}(0.95 \mathrm{M})$ & 2.0 & $360(14)$ \\
\hline 2 & $1000 \mathrm{MW}(3.8 \mathrm{M})$ & 2.0 & $360(56)$ \\
\hline 3 & $500 \mathrm{MW}(1.9 \mathrm{M})$ & 1.6 & $396(32)$ \\
\hline 4 & $500 \mathrm{MW}(1.9 \mathrm{M})$ & 3.6 & $396(14)$ \\
\hline 5 & $500 \mathrm{MW}(1.9 \mathrm{M})$ & 2.0 & $648(16)$ \\
\hline 6 & $500 \mathrm{MW}(1.9 \mathrm{M})$ & 2.0 & $252(40)$ \\
\hline Range & $250-1000 \mathrm{MW}$ & $1.6-3.6$ & $252-648$ \\
\hline
\end{tabular}


The costs for each vector of parameters in Table 3, broken down by process area is provided in Table 4 based on a 1984 EPRI study (Scheck, et al. 1984). These costs are used only to obtain an exponential scaling factor for each process area. The actual cost-models are based on 1990 dollars.

Table 4. Process Area Capital Costs Used for Scaling Parameter Estimation (1982 \$/kW)

\begin{tabular}{|l|l|l|l|l|l|l|l|}
\hline $\begin{array}{l}\text { Process } \\
\text { Area }\end{array}$ & $\begin{array}{l}\text { Case } \\
1\end{array}$ & $\begin{array}{l}\text { Case } \\
2\end{array}$ & $\begin{array}{l}\text { Case } \\
3\end{array}$ & $\begin{array}{l}\text { Case } \\
4\end{array}$ & $\begin{array}{l}\text { Case } \\
5\end{array}$ & $\begin{array}{l}\text { Case } \\
6\end{array}$ & $\begin{array}{l}\text { Base } \\
\text { Case }\end{array}$ \\
\hline 10 & 39.51 & 32.51 & 43.23 & 22.16 & 32.87 & 37.84 & 35.86 \\
\hline 20 & 0.85 & 0.60 & 0.71 & 0.72 & 0.71 & 0.71 & 0.71 \\
\hline 30 & 8.90 & 4.75 & 6.45 & 5.24 & 5.26 & 6.73 & 6.01 \\
\hline 40 & 1.85 & 1.85 & 1.50 & 4.02 & 4.02 & 1.85 & 1.85 \\
\hline Total & 51.11 & 39.71 & 51.89 & 32.14 & $4 r .69$ & 47.13 & 44.43 \\
\hline
\end{tabular}

The mathematical model to describe the sensitivity' $i$ cost models to parameter variations is normalized against the cost for the base case. Th, general form of the cost model for each process area is as shown below:

$$
\frac{P C_{i}}{P C_{i}^{\prime}}=\left(\frac{G}{G^{\prime}}\right)^{f} \times\left(\frac{A /}{1 /} \frac{\prime}{C}\right)^{a} \times\left(\frac{B^{\prime}}{B}\right)^{b} \times\left(\frac{S I L}{S I L^{\prime}}\right)^{c}
$$

where

$\mathrm{PC}_{\mathrm{i}} \quad=$ process area capital, $1^{\curvearrowright}, 0 \$$

$\mathrm{PC}_{\mathrm{i}} /=$ process area capital ase case, $1990 \$$

$\mathrm{G} \quad=$ inlet gas flow, acf ।

$\mathrm{G}^{\prime} \quad=$ inlet gas flow, $r$,se case, acfm

$\mathrm{A} / \mathrm{C} \quad=$ air-to-cloth $\mathrm{r}$ 10, acfm/ft2

$\mathrm{A} / \mathrm{C}^{\prime}=$ air-to-cloth .atio, base case, $\mathrm{acfm} / \mathrm{ft} 2$

B = bags per umpartment

$\mathrm{B}^{\prime}=$ bags $\mathrm{r}:$ compartment, base case

SIL $=$ ash * te to silo, tons $/ \mathrm{hr}$

$\mathrm{SIL}^{\prime}=\mathrm{as}^{\prime}$. rate to silo, base case, tons $/ \mathrm{hr}$

Based $n: 1$ the cost data presented in Table 4, the exponents of the model in equation 1 are estimsted and presented in Table 5. Note that it is important to identify the cases which vary only one parameter from the base case since these allow direct estimation of the exponents. Note also that although the cost numbers in Table 4 are in $\$ / \mathrm{kW}$, total dollar needs to be used in the inodel. Since the mathematical model is multiplicative, the exponents derived in Table 5 are independent of the base case used. ${ }^{2}$ The actual base costs used in the model are based on more

2 e.g. consider two cases of different unit sizes, $G_{1}$ and $G_{2}$ (other than the original base case $G^{\prime}$ ). The process capital cost for the two cases can be written as $\frac{P C_{i}^{1}}{P C_{i}^{2}}=\left(\frac{G_{1}}{G_{2}}\right)^{f}$ from equation 1. This implies that $G_{2}$ can be used as a base case instead of $G^{\prime}$. 
recent EPRI studies for a $250 \mathrm{MW}$ plant, although these costs are not significantly different from those reported in earlier studies.

Table 5. Model Scaling Factors

\begin{tabular}{|l|l|l|l|l|}
\hline Area & $f$ & $a$ & $b$ & $c$ \\
\hline 10 & 0.86 & 0.84 & 0.15 & 0 \\
\hline 20 & 0.75 & 0 & 0 & 0 \\
\hline 30 & 0.55 & 0.29 & 0.275 & 0.083 \\
\hline 40 & 0 & 0 & 0 & 0 \\
\hline
\end{tabular}

In Table 5, some of the exponents have been chosen to be zero. This is because the variations for these process areas are not expected to influence cost. Also note that these values for exponents have been averaged over several cases of available data. Due to the small size of the data set, no statistical analysis has been conducted. The exponents derived in Table 5 have been verified against cost data collected more recently for unit sizes ranging from 125-500 MW (Gaikwad \& Sloat, 1992); therefore the cost model can be used for the range 125-1000 MW.

The total capital requirement for a reverse gas baghouse is calculated as shown in Table 6 below. This includes the direct process capital costs and indirect costs associated with reverse baghouses.

Table 6: Total Capital Requirement

\begin{tabular}{ll}
\hline Component & Cost \\
\hline & \\
Particulate Collector & $\mathrm{PC}_{10}$ \\
Ductwork & $\mathrm{PC}_{20}$ \\
Flyash Handling & $\mathrm{PC}_{30}$ \\
ID fans & $\mathrm{PC}_{40}$ \\
Total Process Capital $^{*}$ & $\mathrm{PC}=\mathrm{PC}_{10}+\mathrm{PC}_{20}+\mathrm{PC}_{30}+\mathrm{PC}_{40}$ \\
General Facilities $^{*}$ & $0.10 \mathrm{PC}$ \\
Engg. \& Home Office Fees $^{*}$ & $0.05 \mathrm{PC}$ \\
Process Contingency $^{*}$ & $0.05 \mathrm{PC}$ \\
Project Contingency $^{*}$ & $0.2 \mathrm{PC}$ \\
Total Plant Cost $^{*}$ & $\mathrm{TPC}=1.31 \mathrm{PC}$ \\
Total Plant Investment (including AFUDC) $^{*}$ & $\mathrm{TPI}=1.063 \mathrm{TPC}(3$ years) \\
Preproduction Cost $^{*}$ & $0.002 \mathrm{TPI}$ \\
Inventory Capital $^{*}$ & 0.005 TPC \\
Total Capital Requirement $^{*}$ & $\mathrm{TCR}=1.002 \mathrm{TPI}+0.005 \mathrm{TPC}$ \\
\hline
\end{tabular}

*These items are based on model default values for indirect cost factors. The IECM allows these factors to be changed by the user. 
The O\&M costs for the reverse-air baghouse consists of the fixed costs and the variable costs. The fixed operating cost consists of labor, maintenance labor, material, filter bags, and administrative labor. A mathematical model for the fixed cost is parametrized on unit size, the $\mathrm{A} / \mathrm{C}$ ratio, bag cost and bag life and is provided by equation 2 below.

$$
\frac{F O M}{F O M^{\prime}}=\left(\frac{G}{G^{\prime}}\right)^{s}+\frac{N_{\text {bags }}}{10^{6}} \times\left(\frac{B C}{B F}\right) \times\left(\frac{G}{G^{\prime}}\right) \times\left(\frac{A / C^{\prime}}{A / C}\right)
$$

where $\mathrm{G}, \mathrm{G} /, \mathrm{A} / \mathrm{C}, \mathrm{A} / \mathrm{C}^{\prime}$ are as defined in equation 1 , and

FOM = fixed operating cost, $\mathrm{M} \$$

FOM' $/$ = fixed operating cost, base case $(0.455 \mathrm{M} \$)$

$\mathrm{G} \quad=$ flue gas flow rate

$\mathrm{G}^{\prime} \quad$ = flue gas flow rate, base case $(0.95 \mathrm{Macfm})$

$\mathrm{A} / \mathrm{C}=$ air-to-cloth ratio, $\mathrm{acfm} / \mathrm{ft}^{2}$

$\mathrm{A} / \mathrm{C}=$ air-to-cloth ratio, base case $\left(2.0 \mathrm{acfm} / \mathrm{ft}^{2}\right)$

$\mathrm{BC}=$ bag cost, $\$$

$\mathrm{BF} \quad=$ bag life, years

$\mathrm{N}_{\text {bags }}=$ numbers of bags in baghouse ( $360 \times 14$ default $)$

$\mathrm{s} \quad=0.48$, exponent developed from data in Table 6.

Notice that the model has been developed largely analytically except that the dependence on unit size is based on data in Table 7 which is based on quotes from vendors (Gaikwad \& Sloat, 1992). Note that equation 2 is such that the base case cannot be changed arbitrarily.

Table 7. Data Used for Scaling Parameter Estimation of O\&M Costs (costs in $\$ / \mathrm{kW}$-yr)

\begin{tabular}{|l|l|l|l|}
\hline O\&M & $125 \mathrm{MW}$ & $250 \mathrm{MW}$ & $500 \mathrm{MW}$ \\
\hline Fixed & 2.80 & 1.82 & 1.36 \\
\hline $\begin{array}{l}\text { Ash } \\
\text { Disposal }\end{array}$ & 2.23 & 2.23 & 2.23 \\
\hline Power & 1.82 & 1.69 & 1.61 \\
\hline
\end{tabular}

The variable cost includes the power cost and ash disposal cost. The ash disposal cost is proportional to the ash generated. The power costs are calculated based on the ID fan power required to overcome the expected pressure drop across the baghouse and the other auxiliary power requirements. The variable operating cost is given by

$$
V O M=c f \times\left[C_{a s h} \times 8760 \times A+C_{\text {power }} \times 8760 \times\left(135 \times \Delta P \times\left(\frac{G}{G^{\prime}}\right)+P_{a u x} \times\left(\frac{G}{G^{\prime}}\right)^{\prime}\right)\right]
$$

where $\mathrm{G}, \mathrm{G}^{\prime}$ are as before and

VOM = variable operating costs, $1990 \$$

cf = capacity factor

A = ash disposal rate, tons/hr

$\mathrm{C}_{\mathrm{ash}}=$ ash disposal cost, $\$ /$ ton, $($ default $=\$ 10.24 /$ ton $)$ 
$\mathrm{C}_{\text {power }}=$ power cost, cents $/ \mathrm{kWh}$

$\mathrm{P}_{\mathrm{aux}}=$ auxiliary power requirement $(323 \mathrm{~kW})$

$\Delta P \quad=$ flange to flange pressure drop, inches of $\mathrm{H}_{2} \mathrm{O}(7.5 \mathrm{in})$

$\mathrm{t} \quad=0.65$, exponent derived from data in Table 6

Notice once again that equation 3 is such that the base case cannot be changed arbitrarily.

\section{A Numerical Example}

We will use a base case of unit size $250 \mathrm{MW}(0.95 \mathrm{Macfm})$, with a $\mathrm{A} / \mathrm{C}$ ratio of $2 \mathrm{acfm} / \mathrm{ft}^{2}$, with 360 bags/compartment, 14 compartments, using Appalachian Medium Sulfur coal (ash content $8 \%$, ash rate to silo $=10.44$ tons $/ \mathrm{hr}$ ). We estimate the cost in 1990 dollars of a unit with the following design parameters:

Size $=500 \mathrm{MW}(1.9 \mathrm{Macfm}), \mathrm{A} / \mathrm{C}=2 \mathrm{acfm} / \mathrm{ft} 2$,

396 bags/compartment, 32 compartments,

Bag life $=4$ years, bag cost $=\$ 80 / \mathrm{bag}$

Capacity factor $=65 \%$, flange-to-flange pressure drop $=7.5 \mathrm{in}$. $\mathrm{H} 2 \mathrm{O}$

Emission limit $=0.01 \mathrm{lb} / \mathrm{MMBtu}(99.86 \%)$, Ash disposal rate $=10.441 \mathrm{tons} / \mathrm{hr}$

Capital Costs $(\$ 1990)$ :

$P C_{10}=10.21 \times\left(\frac{1.9}{0.95}\right)^{0.86} \times\left(\frac{2}{1.6}\right)^{0.81} \times\left(\frac{360}{396}\right)^{0.15}=21.89 M \$$

$P C_{20}=0.3325 \times\left(\frac{1.9}{0.95}\right)^{0.75}=0.56 M \$$

$P C_{30}=2.06 \times\left(\frac{1.9}{0.95}\right)^{0.55} \times\left(\frac{2}{1.6}\right)^{0.29} \times\left(\frac{360}{396}\right)^{0.275} \times\left(\frac{10.44}{5.22}\right)^{0.083}=3.32 M \$$

$P C_{40}=0.19 M \$$

$P C=21.89+0.56+3.32+0.19=25.96 M \$$

General Facilities $=0.26 \mathrm{M} \$$

Engg. \& Home $=1.9 \mathrm{M} \$$

Proc. Contingency $=1.9 \mathrm{M} \$$

Proj. Contingency $=5.2 \mathrm{M} \$$

TPC $=35.21 \mathrm{M} \$$

TPI $\quad=37.43 \mathrm{M} \$$

Preproduction cost $=0.075 \mathrm{M} \$$

Inventory capital $=0.176 \mathrm{M} \$$

Total Capital Req. $=37.68 \mathrm{M} \$(\$ 75.4 / \mathrm{kW})$ 
Fixed Costs:

$F O M=0.455 \times\left(\frac{1.9}{0.95}\right)^{0.48}+\frac{396 \times 14}{1 \times 10^{6}} \times\left(\frac{80}{4}\right) \times\left(\frac{1.9}{0.95}\right) \times\left(\frac{2}{1.6}\right)=0.91 M \$ / y r$

Variable Cost::

$$
\begin{aligned}
V O M & =0.65 \times\left(\frac{10.24 \times 8760 \times 10.441}{1 \times 10^{6}}+\frac{0.0554 \times 8760}{1 \times 10^{6}} \times\left[135 \times 7.5 \times\left(\frac{1.9}{0.95}\right)+323 \times\left(\frac{1.9}{0.95}\right)\right]\right) \\
& =2.22 \mathrm{M} \text { \$ i yr }
\end{aligned}
$$

\subsubsection{Pulse-Jet Systems}

The experimental design used to choose different vectors of design parameters for capital costs are shown in Table 8 below. However, since Pulse-Jet fabric filters are evaluated with three different levels of pressure jets (low, intermediate, and high pressure) this design is used three times, once for each pressure level.

Table 8. Design Parameters for Pulse-Jet Systems

\begin{tabular}{|l|l|l|l|}
\hline Case & $\begin{array}{l}\text { Size in MW } \\
(\mathrm{M} \text { acfm })\end{array}$ & $\begin{array}{l}\mathrm{A} / \mathrm{C} \text { Ratio (gross) } \\
\mathrm{acfm}^{2} \mathrm{ft}^{2}\end{array}$ & $\begin{array}{l}\text { Bag length } \\
\text { feet }\end{array}$ \\
\hline Base & $250(0.9)$ & 4 & 20 \\
\hline 1 & $125(0.475)$ & 4 & 20 \\
\hline 2 & $500(1.9)$ & 4 & 20 \\
\hline 3 & $250(0.9)$ & 3 & 20 \\
\hline 4 & $250(0.9)$ & 6 & 20 \\
\hline 5 & $250(0.9)$ & 4 & 15 \\
\hline 6 & $250(0.9)$ & 4 & 25 \\
\hline Range & $125-500$ & $3-6$ & $15-25$ \\
\hline
\end{tabular}

The costs for each vector of parameters in Table 8 broken down by process area is based on recent EPRI data for low, intermediate, and high pressure Pulse-Jet fabric filters (Gaikwad \& Sloat, 1992).

The mathematical model to describe the sensitivity of the cost models to parameter variations again is normalized against the cost for the base case. The generalized form of the model for each process area is shown below:

$$
\frac{P C_{i}}{P C_{i}^{\prime}}=\left(\frac{G}{G^{\prime}}\right)^{j} \times\left(\frac{A / C^{\prime}}{A / C}\right)^{k} \times\left(\frac{B L^{\prime}}{B L}\right)^{l} \times\left(\frac{B C}{B C^{\prime}}\right)^{m} \times\left(\frac{S I L}{S I L^{\prime}}\right)^{i}
$$

where

$\mathrm{PC}_{\mathrm{i}} \quad=$ process area capital, $\mathrm{M} \$$

$\mathrm{PC}_{\mathrm{i}} /$ = process area capital, base case, $\mathrm{M} \$$

$\mathrm{G} \quad=$ inlet gas flow, acfm

$\mathrm{G}^{\prime}=$ inlet gas flow, base case, acfm 
$\mathrm{A} / \mathrm{C}=$ air-to-cloth ratio, $\mathrm{acfm} / \mathrm{ft}^{2}$

$\mathrm{A} / \mathrm{C}^{\prime}=$ air-to-cloth ratio, base case, $\mathrm{acfm} / \mathrm{ft}^{2}$

BL = bag length, feet

$\mathrm{BL}^{\prime}=$ bag length, base case, feet

$\mathrm{BC} \quad=$ bag cost $\$ / \mathrm{bag}$

$\mathrm{BC}^{\prime}=$ bag cost, base case, $\$ / \mathrm{bag}$

SIL = ash rate to silo, tons $/ \mathrm{hr}$

$\mathrm{SIL}^{\prime}=$ ash rate to silo, base case, tons $/ \mathrm{hr}$

$\mathrm{i}, \mathrm{j}, \mathrm{k}, \mathrm{l}, \mathrm{m}=$ exponents derived from data

The estimated exponents of the model in Equation 4 are presented in Table 9. The model is once again independent of the base case used.

Table 9. Exponents for Equation 4

\begin{tabular}{|l|l|l|l|l|l|}
\hline Area & $j$ & $k$ & $l$ & $m$ & $i$ \\
\hline 10 & 0.85 & 0.72 & 0.44 & 0.15 & 0 \\
\hline 20 & 0 & 0 & 0 & 0 & 0 \\
\hline 30 & 0.56 & 0.12 & 0.10 & 0 & 0.13 \\
\hline 40 & 0 & 0 & 0 & 0 & 0 \\
\hline
\end{tabular}

In Table 9 some of the exponents are chosen to be zero since they do not influence the capital costs. All exponents for the process area 40 is chosen zero since the slight variation in cost is not consistent with the economics of scale. Moreover, the cost of process area 40 is less than $5 \%$ of the total process cost.

As with reverse gas baghouses, the O\&M costs for pulse-jet baghouses consists of fixed and variable costs. The fixed operating costs consists of labor, maintenance labor, material, filter bags, and administrative labor. The mathematical model for the fixed costs is parametrized on unit size, $\mathrm{A} / \mathrm{C}$ ratio, bag cost and bag life shown in equation 5 below.

$$
\frac{F O M}{F O M^{\prime}}=\left(\frac{F}{F^{\prime}}\right)^{u}+\frac{N_{\text {bags }}}{10^{6}} \times\left(\frac{B C}{B F}\right) \times\left(\frac{G}{G^{\prime}}\right) \times\left(\frac{A / C^{\prime}}{A / C}\right)
$$

where $\mathrm{F}, \mathrm{F}^{\prime}, \mathrm{A} / \mathrm{C}, \mathrm{A} / \mathrm{C}^{\prime}$ are as defined in equation 1 , and

FOM = fixed operating cost, $M \$$

$\mathrm{FOM}^{\prime}$ =fixed operating cost, base case, $0.6325 \mathrm{M} \$$

$\mathrm{G}=$ flue gas flow rate

$\mathrm{G}^{\prime} \quad=$ flue gas flow rate, base case, 0.95 Macfm

$\mathrm{A} / \mathrm{C}=$ air-to-cloth ratio, $\mathrm{acfm} / \mathrm{ft} 2$

$\mathrm{A} / \mathrm{C}=$ air-to-cloth ratio, base case, $2 \mathrm{acfm} / \mathrm{ft}^{2}$

$\mathrm{BC}=$ bag cost, $\$$, (default $\$ 80$ )

$\mathrm{BF}=$ bag life, years, (default 3 years)

$\mathrm{N}_{\text {bags }}=$ numbers of bags in baghouse, (default 9050 )

$\mathrm{u} \quad=0.63$ exponent developed from data in Table 9 . 
This model has been developed largely analytically, however, the dependence on unit size is based on data in Table 10 below (Gaikwad \& Sloat, 1992).

Table 10. Relative O\&M costs Used for Scaling Factor Estimation (in \$/kW-yr)

\begin{tabular}{|l|l|l|l|}
\hline O\&M & $125 \mathrm{MW}$ & $250 \mathrm{MW}$ & $500 \mathrm{MW}$ \\
\hline Fixed & 3.45 & 2.53 & 2.07 \\
\hline Ash & 2.23 & 2.23 & 2.23 \\
\hline Power & 2.06 & 1.96 & 1.88 \\
\hline
\end{tabular}

The variable costs, as before, includes power cost and ash disposal costs. The variable operating cost is given by equation 6 below:

$V O M=c f \times\left[C_{\text {ash }} \times 8760 \times A+C_{\text {power }} \times 8760 \times\left(135 \times \Delta P \times\left(\frac{G}{G^{\prime}}\right)+P_{\text {aux }} \times\left(\frac{G}{G^{\prime}}\right)^{w}\right)\right]$

where $\mathrm{F}, \mathrm{F}^{\prime}$ are as before and

VOM = variable operating costs, $\$$

cf = capacity factor

A = ash disposal rate, tons $/ \mathrm{hr}$

$\mathrm{C}_{\text {ash }}=$ ash disposal cost, \$/ton

$\mathrm{C}_{\text {power }}=$ power cost, cents/KWh (default 5.54)

$\mathrm{P}_{\text {aux }}=$ auxiliary power requirement, $742 \mathrm{~kW}$

$\Delta \mathrm{P} \quad=$ flange to flange pressure drop, inches of $\mathrm{H} 2 \mathrm{O}$

$\mathrm{w} \quad \mathbf{0} .85$, exponent derived from data in Table 10

Notice once again that equation 6 is such that the base case cannot be changed arbitrarily.

A Numerical Example for Pulse-Jet Baghouses

We will estimate the capital and operating costs for a pulse-jet baghouse for the same design parameters as used in the example for reverse-gas baghouses. (Refer to Table 6 for indirect costs).

(see following page) 
Capital Costs (1990 \$):

$P C_{10}=5.925 \times\left(\frac{1.9}{0.95}\right)^{0.85} \times\left(\frac{4}{3}\right)^{0.72} \times\left(\frac{20}{15}\right)^{0.44}=14.9 M \$$

$P C_{20}=0.375 M \$$

$P C_{30}=2.155 \times\left(\frac{1.9}{0.95}\right)^{0.56} \times\left(\frac{4}{3}\right)^{0.12} \times\left(\frac{20}{15}\right)^{0.1} \times\left(\frac{10.44}{5.22}\right)^{0.13}=3.70 M \$$

$P C_{40}=0.19 M \$$

Total Process Capital $(\mathrm{PC})=19.165 \mathrm{M} \$$

General Facilities $\quad=0.19 \mathrm{M} \$$

Engg.\&Home Office $\quad=0.96 \mathrm{M} \$$

Process Contingency $\quad=1.9 \mathrm{M} \$$

Project Contingency $\quad=3.8 \mathrm{M} \$$

Total Plant Cost (TPC) $\quad=26.0 \mathrm{M} \$$

TPI $=27.65 \mathrm{M} \$$

Preproduction costs $\quad=0.055 \mathrm{M} \$$

Inventory Capital $\quad=0.13 \mathrm{M} \$$

Total Capital Requirement $\quad=27.835 \mathrm{M} \$(\$ 55.7 / \mathrm{kW})$

Fixed Costs:

$F O M=0.6325 \times\left(\frac{1.9}{0.95}\right)^{0.63}+\frac{360 \times 14}{10^{6}} \times\left(\frac{80}{4}\right) \times\left(\frac{1.9}{0.95}\right) \times\left(\frac{4}{3}\right)=1.78 M \$ / y r$

Variable Costs:

$V O M=\frac{0.65}{1 \times 10^{6}} \times\left(10.24 \times 8760 \times 10.44+0.0554 \times 8760 \times\left[135 \times 6.7 \times\left(\frac{1.9}{0.95}\right)+742 \times\left(\frac{1.9}{0.95}\right)^{0.85}\right]\right)$ $=1.6 \mathrm{M} \$ / \mathrm{yr}$

\section{References}

Belba, V. H., Grubb, W. T., \& Chang, R. (1992). The Potential of Pulse-Jet Baghouses for Utility Boilers. Part 1: A Worldwide Survey of Users. J. Air Waste Manage. Assoc., 42(2), 209.

Bustard, C. J., Cushing, K. M., \& Chang, R. L. (1992). The Potential of Pulse-Jet Baghouses for Utility Boilers. Part 2: Performance of Pulse-Jet Fabric Filter Plants. J. Air Waste Manage. Assoc., 42(9), 1240.

Carr, R. C., \& Smith, W. B. (1984). Fabric Filter Technology for Utility Coal-Fired Power Plants: A Series of Articles Reprinted from the "J. of Air Pollution Control Association" No. EPRI CS-3754-SR). Electric Power Research Institute. 
Cushing, K. M., Bush, P. V., \& Synder, T. R. (1990). Operating history and current status of fabric filters in the utility industry. J. Air Waste Manage. Assoc., 40, 1051.

Gaikwad, R. P., \& Sloat, D. G. (1992). Economic Evaluation of Particulate Control Technologies No. EPRI TR-100748). Electric Power Research Institute.

Kumar, K. S., \& Feldman, P. L. (1994). Electrostatic Precipitators versus Fabric Filters: Fact versus Fiction. In Electrostatic Precipitators versus Fabric Filters: A Symposium and Debate, . Crystal City, VA: ICAC.

Puille, W. (1985). 1985 Update, Operating History and Current Status in the Utility Industry. In Third Conference on Fabric Filter Technology for Coal Fired Power Plants, . Scottsdale, AZ:

Scheck, R. W., Mora, R. H., Belba, V. H., \& Horney, F. A. (1985). Economics of Fabric Filters and Electrostatic Precipitators No. EPRI CS-4083). Electric Power Research Institute.

Sloat, D. G., Gaikwad, R. P., \& Chang, R. L. (1993). The Potential of Pulse-Jet Baghouses for Utility Boilers. Part 3: Comparative Economics of Pulse-Jet Baghouse, Precipitators and Reverse-Gas Baghouses. J. Air Waste Manage. Assoc., 43, 120. 

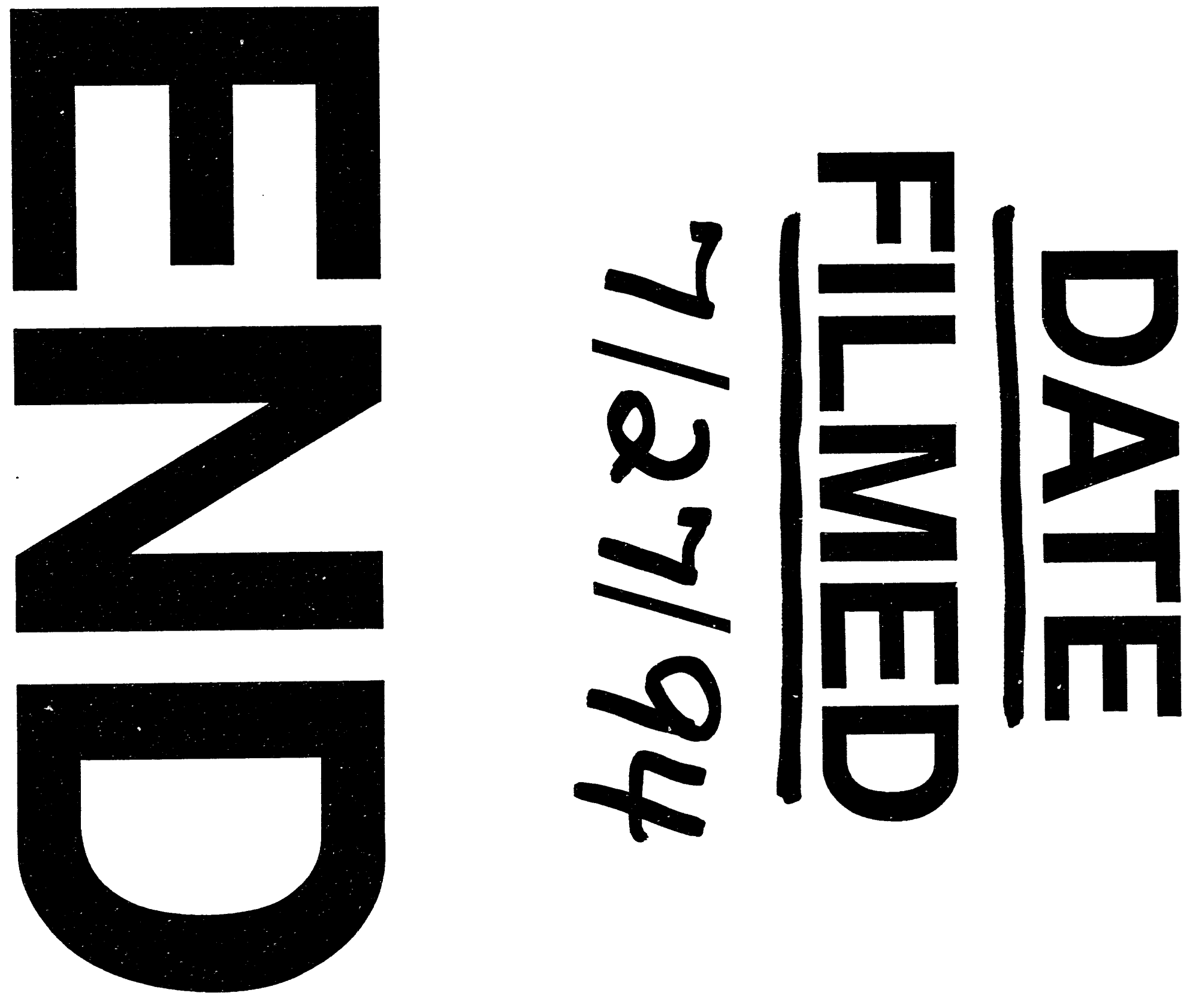
